\title{
Interactions between biological and environmental structures along the coast of northern Norway
}

\author{
Maria Fossheim ${ }^{1, *}$, Meng Zhou ${ }^{2}$, Kurt S. Tande ${ }^{1}$, Ole-Petter Pedersen $^{1}$, Yiwu Zhu ${ }^{2}$, \\ Are Edvardsen ${ }^{1}$
}

\author{
${ }^{1}$ Norwegian College of Fishery Science, University of Tromsø, 9037 Tromsø, Norway \\ ${ }^{2}$ EEOS Department, University of Massachusetts Boston, Boston, Massachusetts 02125, USA
}

\begin{abstract}
Spatial and temporal variability in physical conditions off the northern coast of Norway may affect the 3D distribution of mesozooplankton and capelin larvae (Mallotus villosus Müller) during the early capelin recruitment period. To monitor distribution patterns, we sampled the water masses down to $100 \mathrm{~m}$ on 3 successive occasions in May 2001 with a SCANFISH-OPC-CTD-F platform. We found distinct differences between coastal and oceanic waters in the study area. The water masses were most clearly distinguished by salinity and there was a tendency for higher zooplankton abundance and biomass in water of oceanic origin. Our study area was characterised by mesoscale eddies, translating in an easterly direction which follow the Norwegian Coastal Current. Cyclonic eddies contained oceanic water, high zooplankton abundance and biomass, whereas anti-cyclonic eddies contained water masses of coastal origin and low abundance of zooplankton. The eddies found in the spawning and hatching habitat of capelin were relatively small and of short duration; however, their impact on the biological community in terms of mediating exchange of biotas across the shelf can be significant.
\end{abstract}

KEY WORDS: Optical plankton counter · Eddy $\cdot$ Barents Sea $\cdot$ Capelin larvae

\section{INTRODUCTION}

Spawning sites of capelin Mallotus villosus Müller are often found in fjords and adjacent areas on the shelf of northern Norway (Gjøsæter 1998), where tidal-, wind- and density-driven currents and coastal up- or downwelling events interact (Harms 1992, McClimans \& Nilsen 1993). The southern Barents Sea is dominated by interactions of 2 waters: coastal water and Atlantic water (Loeng 1991), and the mixing of these 2 waters prevails in the hatching and nursery areas of capelin larvae. Mesoscale hydrographical features such as fronts and eddies dominate in this area (Pedersen et al. 2005), and may affect larval survival and subsequently recruitment. After hatching, the fish larvae are transported offshelf towards nurseries in the central part of the Barents Sea, and few larvae remain in the coastal area after 2 wk (Gjøsæter 1998, Pedersen et al. 2003). The strategic programme BASECOEX ('Capelin and
Herring in the Barents Sea-Coexistence or Exclusion') is a multidisciplinary research project attempting to understand capelin-herring interactions in the Barents Sea. During the project, field surveys were undertaken to resolve the 3D advection, migration and in situ population dynamic rates of capelin larvae and zooplankton in a core spawning area of capelin.

Mesoscale eddies have been observed within coastal current systems on numerous continental shelves, including within the Benguela Current (Bang 1973), the Florida Current (Lee \& Mayer 1977), the Gulf Stream off North America (Csanady 1979), the Norwegian Coastal Current (Ikeda et al. 1989), the Irish Shelf front (Huang et al. 1991), the Gulf of Alaska (Bograd et al. 1994) and the Barents Sea (Pedersen et al. 2005). The length and timescales of eddies vary geographically but are typically between 10 and $50 \mathrm{~km}$ and 1 and $4 \mathrm{wk}$, respectively. Mesoscale eddies can contribute to the retention or dispersal of planktonic organisms 
(Lobel \& Robinson 1986, Boehlert et al. 1992, Bograd et al. 1994, Rodriguez et al. 2001, Halvorsen et al. 2003) and affect the biological productivity of coastal regions (Rey 1981, Kimura et al. 1997, Kasai et al. 2002). An eddy can concentrate buoyant passive materials when its secondary circulation converges. This mechanism may aggregate patches of plankton in confined areas and may provide favourable retention areas (Halvorsen et al. 2003). A divergent eddy on the other hand may increase primary production due to the upwelling of nutrient-rich deep water to the euphotic surface layer, which may further enhance zooplankton production (Kimura et al. 1997, Nakata et al. 2000).

Abundant fish larvae have previously been observed in both cyclonic (Okazaki et al. 2002) and anti-cyclonic (Schumacher et al. 1993) eddies. Canino et al. (1991) suggested that feeding and survival conditions may be better in eddies. Bograd et al. (1994) found that larvae retained within an eddy had a lower mortality rate than elsewhere. It has also been hypothesised that retention in eddies, that move downstream at slower rates than mean currents (Bograd et al. 1994), aid in delivering larvae to the nurseries. Eddies may aid in retention of fish larvae in coastal areas (Kasai et al. 2002) and may decrease the likelihood of them being transported into the oceanic regime (Bograd et al. 1994), or may function as a transport mechanism from coastal areas to offshore nursery grounds (Komatsu et al. 2002). Eddies are also important for larvae in helping them to avoid excessive transport (i.e. currents may carry them away from the nurseries) by retaining them in areas that are conducive to their survival (Hinckley et al. 2001). Young larvae are more likely to survive in a healthy environment if that environment includes an eddy (Bograd et al. 1994, Okazaki et al. 2003).

The present study describes the physical and biological environment in an important spawning habitat of capelin during the period of larval hatching. The objective was to determine, in particular, how the spatial and temporal variability in physical conditions dictate the 3D distribution patterns of mesozooplankton and capelin larvae and investigate the possible role of mesoscale eddies in the along-shelf and offshelf transport of capelin larvae after their release from the seabed.

\section{MATERIALS AND METHODS}

Survey and study area. The study area in the southern Barents Sea in May 2001 (Fig. 1) was chosen because of the high concentrations of capelin larvae detected by a MultiNet (MultiNet MiDi; Hydro-Bios Apparatebau). A grid ( 71 to $71^{\circ} 20^{\prime} \mathrm{N}, 25$ to $29^{\circ} \mathrm{E}$ ) of approximately $6 \times 10^{3} \mathrm{~km}^{2}$ outside the 2 fjords Porsangerfjord and Laksefjord was surveyed on 3 successive occasions (Phases 1, 2 and 3). During each phase, the area was sampled by a towed, undulating vehicle (MKII SCANFISH, GMI, Snekkersten, Denmark) that sampled the water column from 1 to $100 \mathrm{~m}$. An optical plankton counter (OPC; Focal Technologies) (Herman 1988, 1992) was mounted on the SCANFISH together with a CTD (Sea-Bird 911; Sea-Bird Electronics) and a fluorometer (Seapoint chlorophyll fluorometer; Seapoint Sensors). The OPC detects particles in 4096 digital sizes within a range of 0.25 to $14 \mathrm{~mm}$ equivalent

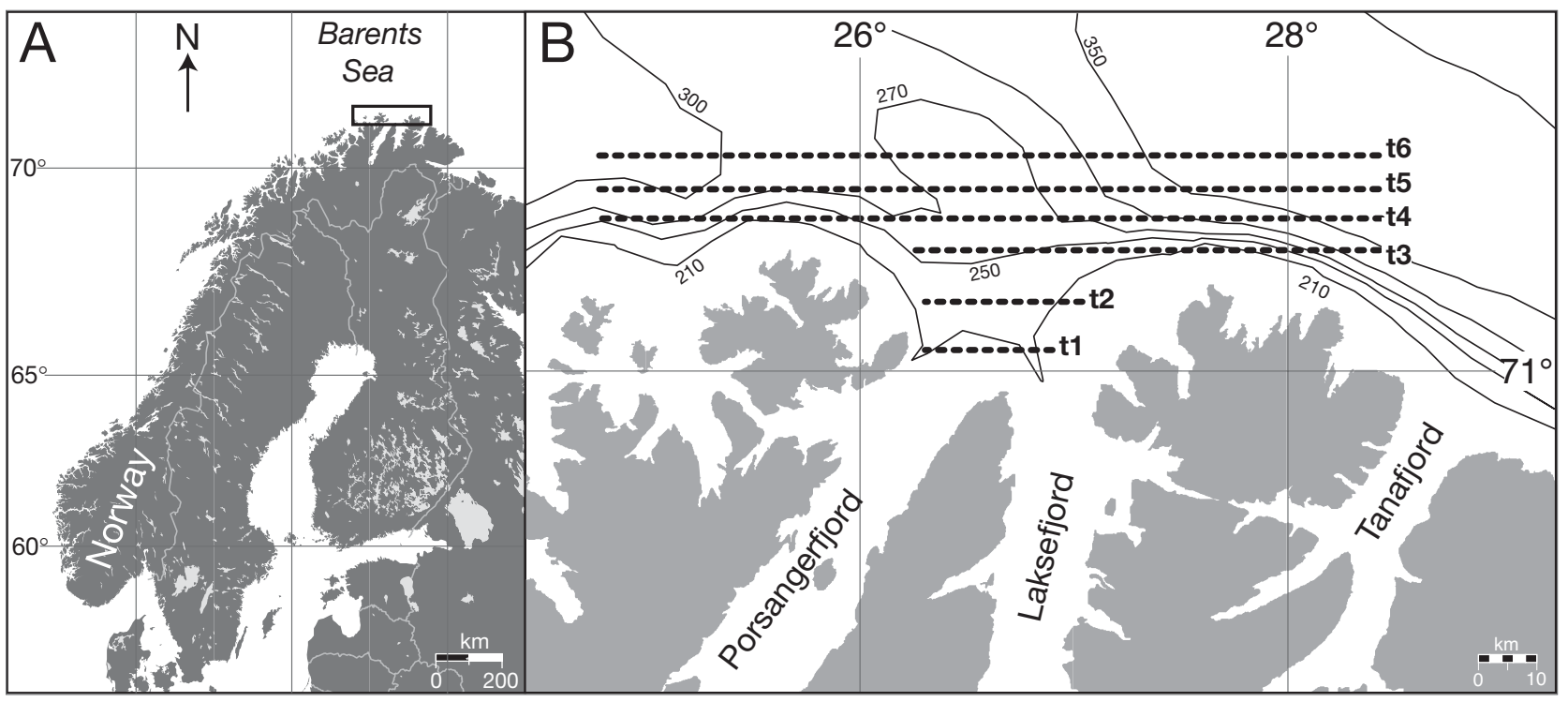

Fig. 1. (A) Map of Scandinavia showing location of study area (box); (B) study area in the southern Barents Sea, showing the 3 fjords Porsangerfjord, Laksefjord and Tanafjord and idealised Transect Lines t1 (inner) to t6 (outer) 
spherical diameter (ESD), and measures abundance of zooplankton (individuals $\mathrm{m}^{-3}$ ) and individual sizes (see Edvardsen et al. 2002 for further details). The CTD measures conductivity (i.e. salinity), temperature and depth. The flow was monitored outside the OPC by a flowmeter (Model 2135; General Oceanics).

Each phase lasted for approximately $5 \mathrm{~d}$, consisting of 1 or $2 \mathrm{~d}$ of the SCANFISH coverage followed by $3 \mathrm{~d}$ of conventional sampling of hydrography and plankton using vertical CTD-F casts and MOCNESS (multiple opening-closing nets and environmental sensing system) (Wiebe et al. 1976, 1985) at approximately 9 stations covering the survey area in each phase. Phase 1 (17 May) was terminated after 3 transects due to OPC failure. In Phases 2 (21 to 23 May) and 3 (28 to 30 May), all 6 transects (from t1, closest to the coast, to t6, furthest from the coast) were sampled (Fig. 1). The survey area varied between phases: Phase 2 transects reached further to the west while Phase 3 transects reached further to the southeast, including the area outside Tanafjord.

Data processing. Data from the various instruments onboard the ship and the SCANFISH were integrated to provide a data set containing spatial (i.e. latitude, longitude, depth) and environmental (temperature, salinity, fluorescence, zooplankton abundance) variables. After processing the raw data, each variable of the data set represented an average over a period of $5 \mathrm{~s}$. In addition to the abundance of zooplankton (individuals $\mathrm{m}^{-3}$ ), the biomass in carbon was also estimated. The zooplankton carbon weight $(W)$ was calculated from body length $(L)$ given by the ESD (Huntley et al. 1995) and the relation of Rodriguez \& Mullin (1986): $\log W[\mu \mathrm{gC}]=2.23 \log L[\mu \mathrm{m}]-5.58$. This relation is applicable to zooplankton in our study area at the first order of approximation. For interpolation and smoothing the measured field objective analysis (OA) was applied (Gandin 1963, Bretherton et al. 1976). OA is basically a contemporary synonym for statistical estimation based on the Gauss-Markov theorem. The correlation function applied is the same as that presented in Zhou (1998). The major advantage of OA is that the method yields an estimate at every point $(x, y, z, t)$ which is optimal to the least square error. Abundance and biomass estimates for the 3 phases are shown.

The digital size spectrum measured by the OPC was integrated into 60 size classes of equal log (ESD) increments. We use the definition of a normalised biomass spectrum (simply referred to as a biomass spectrum) used in previous literature (Sheldon \& Parsons 1967, Platt \& Denman 1978, Silvert \& Platt 1978, Zhou \& Huntley 1997), i.e.

biomass spectrum $=$

$$
\frac{\text { biomass in the size interval } \Delta W}{\text { the size interval } \Delta w}\left(\text { in }^{-3}\right)
$$

where the size $(w)$ of zooplankton is the body biomass in carbon. Because an OPC provides ESD measurements of zooplankton, the body volumes of zooplankton can be converted directly from ESD. The biovolume spectrum $(b)$ is defined as

biovolume spectrum $(b)=$

$$
\frac{\text { biovolume in the size interval } \Delta v}{\text { the size interval } \Delta v}\left({\text { in } \mathrm{m}^{-3}}^{-3}\right)
$$

where the size $(v)$ of zooplankton is the body volume in $\mathrm{mm}^{3}$. Although the relation between the body biomass and volume can vary between species, the biovolume spectrum should be equivalent to the biomass spectrum on the first order of approximation. To avoid further complication and uncertainty in the relations between the body biomass and volume for different species compositions, we simply use biovolume and biovolume spectra in our computations and discussion. We present the biovolume spectra vs. corresponding ESD instead of individual biovolume to better visualize plankton sizes.

The zooplankton community structure was known from conventional sampling with the MOCNESS. Since there is a growing evidence that the MOCNESS and the OPC sample the zooplankton community differently (Edvardsen et al. 2002), we have to be cautious when comparing the abundance of zooplankton from the MOCNESS with the abundance output from the OPC size spectra. Species present in more than $1 \%$ of the total abundance in the MOCNESS samples were considered to contribute to the OPC data, and the species was assigned to a size group as follows: in the laboratory, OPC size measurements were conducted on monocultures of all copepodite stages and adult females for Calanus finmarchicus together with Thysanoessa spp. furcilia and newly hatched capelin larvae (A. Edvardsen \& M. Fossheim unpubl. data). Other groups were assigned to a size group based on literature sources describing their prosome sizes and body volumes. These gave a total of 6 new groups, all in size ranges much lower than capelin larvae, except for Oikopleura spp, whose actual body size was estimated to be within a size range similar to that of capelin larvae (M. Fossheim pers. obs.). In the following, we use the OPC data as size structured abundance information on zooplankton, bearing in mind that linking this type of data to species information must be done with great care.

Statistical analysis. To document spatial variation in the physical and biological structures, we compared the particle abundance in different eddies identified in the 3 outer transects (t4 to t6) in Phase 3. Because of strong autocorrelation, the data set was halved, and only the downward part of every SCANFISH profile (5 to $95 \mathrm{~m}$ ) was chosen. An average for every profile was then calculated, 9 profiles $(n=9)$ were selected in the core of each physical structure, and a 2-factor (transect and 
eddy) ANOVA was performed followed by post-hoc $t$-tests (with Bonferroni corrections). The null hypothesis $\left(H_{0}\right)$ states that there are no differences in particle abundance between different physical structures (eddies).

\section{RESULTS}

The present paper provides a simultaneous analysis of the main hydrodynamic features together with biological information in terms of abundance and biomass. This information is presented below for each phase.

\section{Phase 1 (Fig. 2)}

The area close to the outlet of Porsangerfjord and Laksefjord was dominated by water of coastal origin (Fig. 2), of low temperature $\left(<5^{\circ} \mathrm{C}\right)$ and salinity $(<34.7 \%$ ), along the 2 inner transects ( 11 and $\mathrm{t} 2)$. Along transect t3 $\left(26^{\circ} 30^{\prime}\right.$ to $\left.27^{\circ} 00^{\prime} \mathrm{E}\right)$, coastal water occupied its middle west section while oceanic water of high temperature $\left(>5^{\circ} \mathrm{C}\right)$ and salinity $(>34.8 \%$ ) occupied both sides. The abundance of zooplankton was highest (max. $7 \times 10^{3}$ ind. $\mathrm{m}^{-3}$ ) in the deeper part of the water column (below $50 \mathrm{~m}$ ), particularly in the inner transects (t1 and t2), where temperature and salinity were low. In contrast, the biomass was high throughout the whole water column (max. $\sim 1.5 \times 10^{5} \mu \mathrm{g} \mathrm{m}^{-3}$ ).

\section{Temperature $\left({ }^{\circ} \mathrm{C}\right)$}

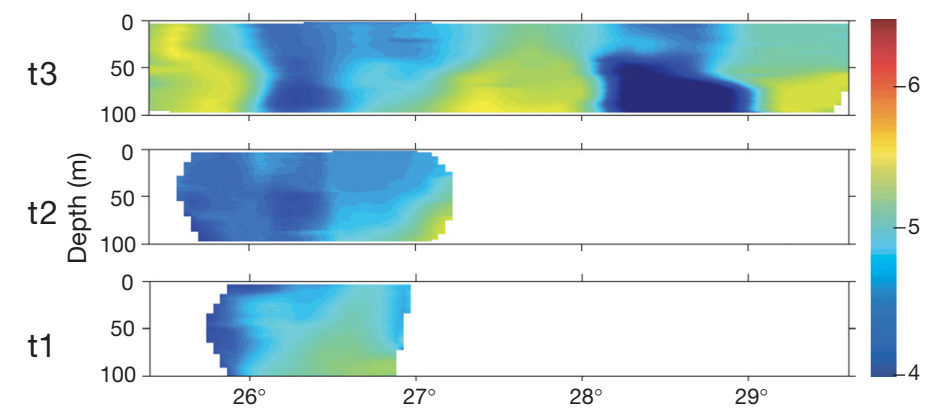

Abundance (ind. $\mathrm{m}^{-3}$ )

t3

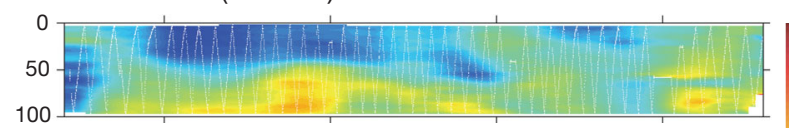

t2

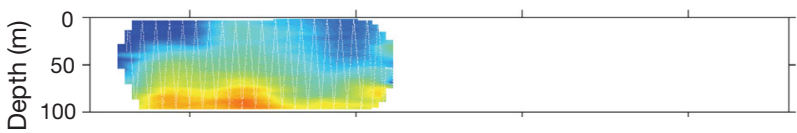

$\mathrm{t} 1$

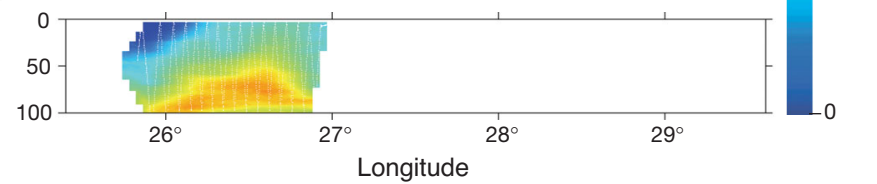

Phase 2 (Fig. 3)

In the inner part of the study area, which was surveyed during all phases, hydrographic conditions changed between Phases 1 and 2 (Fig. 3). More saline water $(>34.8 \%$ ) now dominated the inner shelf (t2 and t3). Oceanic water (temperature $>5^{\circ} \mathrm{C}$, salinity $>34.9 \%$ ) dominated in the outer area, but was interspersed by several wedges of coastal water. The abundance of zooplankton was low $\left(\sim 3 \times 10^{3}\right.$ ind. $\left.\mathrm{m}^{-3}\right)$ in the western area of the study region, concurrent with relatively low salinity coastal water. High zooplankton abundance (max. $7.5 \times 10^{3}$ ind. $\mathrm{m}^{-3}$ ) was found in oceanic water in outer transect t 6 and on the eastern rim of inner transect $\mathrm{t} 3$ (max. $8 \times 10^{3}$ ind. $\mathrm{m}^{-3}$ ). Biomass distribution showed the same pattern as abundance (maxima $2 \times 10^{5} \mu \mathrm{g} \mathrm{m}^{-3}$ in $\mathrm{t} 3$, and $1.7 \times 10^{5} \mathrm{\mu g} \mathrm{C} \mathrm{m}^{-3}$ in t6).

\section{Phase 3 (Fig. 4)}

The hydrographic conditions changed again between Phases 2 and 3 . Conditions in the area just outside the 2 fjords now resembled those during Phase 1, with more coastal water close to the outlet of Porsangerfjord and Laksefjord (Fig. 4). The inner transects (t1 and t2) covered an area containing coastal water (temperature $<5^{\circ} \mathrm{C}$, salinity $<34.5 \%$ ). This coastal water plume
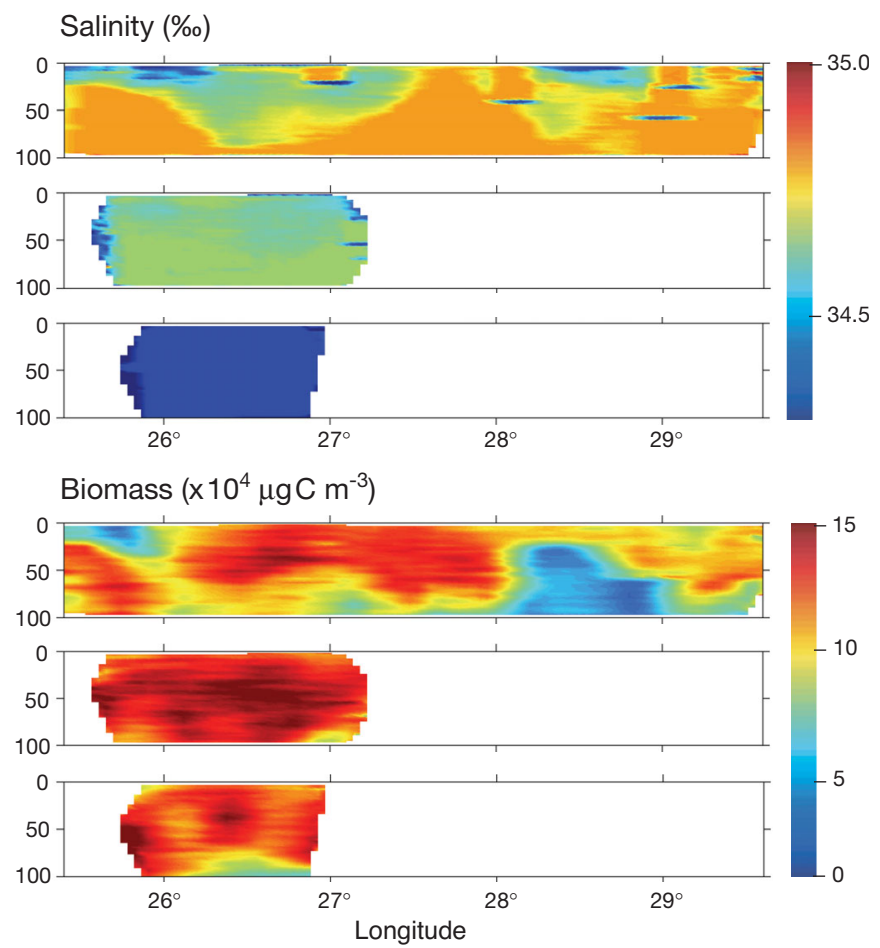

Fig. 2. Temperature $\left({ }^{\circ} \mathrm{C}\right)$, salinity $(\%)$, abundance (ind. $\mathrm{m}^{-3}$ ) and biomass $\left(\mu \mathrm{g} \mathrm{C} \mathrm{m}{ }^{-3}\right)$ of zooplankton along the major transects (t1 to $\mathrm{t} 3)$ in the southern Barents Sea in Phase 1 (17 May) 

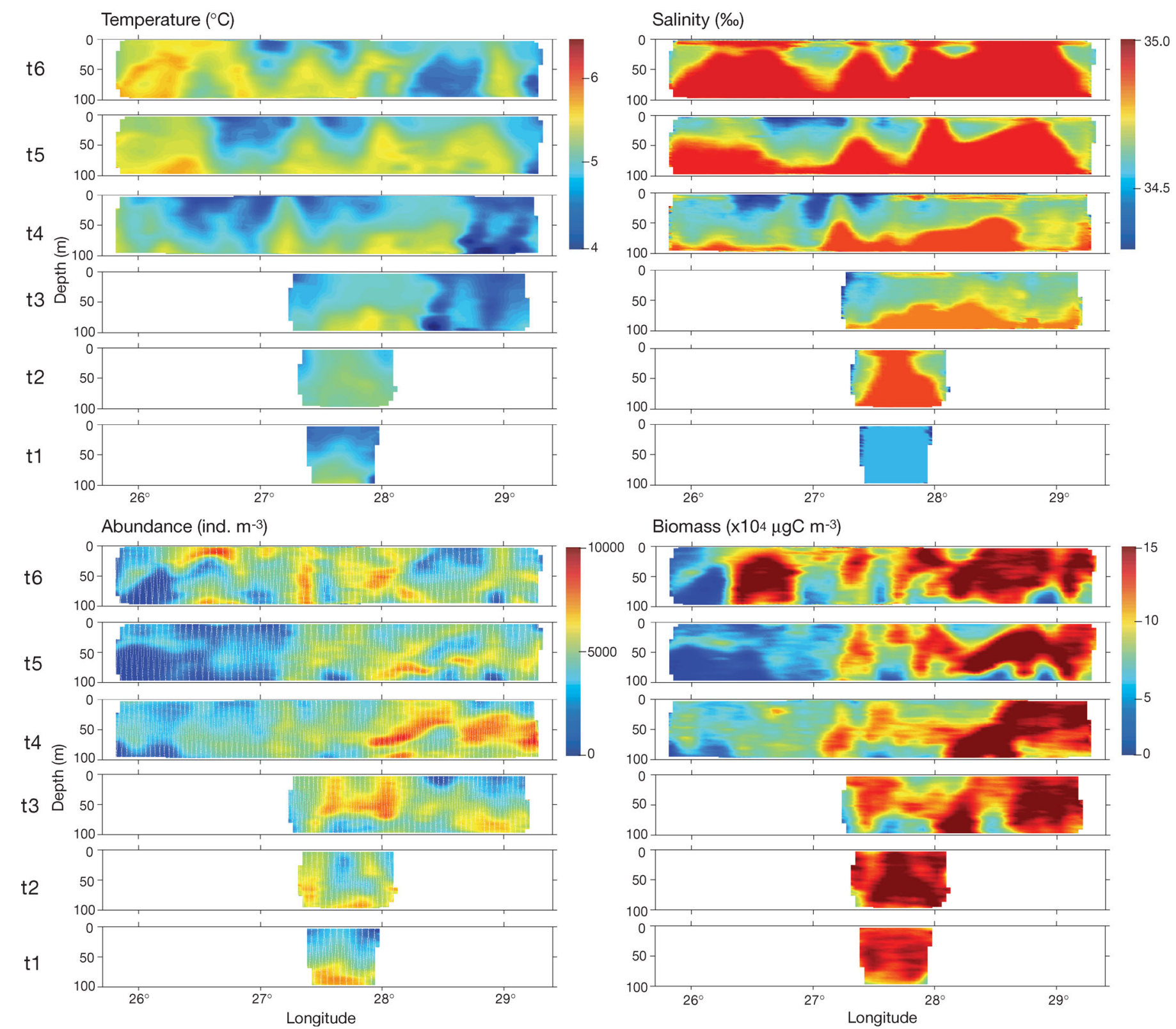

Fig. 3. Temperature $\left({ }^{\circ} \mathrm{C}\right)$, salinity $(\%)$, abundance (ind. $\mathrm{m}^{-3}$ ) and biomass $\left(\mu \mathrm{g} \mathrm{C} \mathrm{m}^{-3}\right)$ of zooplankton along the major transects (t1 to t6) in the southern Barents Sea in Phase 2 (21 to 23 May)

continued through the middle of all transects. On both sides of this coastal water in transects 4 to 6 , oceanic waters were found (temperature $>5^{\circ} \mathrm{C}$, salinity $>34.9 \%$ ). Along the eastern rim of the study area, from t3 to $\mathrm{t} 6$ just outside Tanafjord, the water became less saline and colder (temperature $<5^{\circ} \mathrm{C}$, salinity $<34.7 \%$ ). The abundance of zooplankton was generally higher in oceanic waters, with maximum numbers of $\sim 6 \times$ $10^{3}$ ind. $\mathrm{m}^{-3}$. The biomass (maxima $\sim 1.5 \times 10^{5} \mathrm{\mu g} \mathrm{C} \mathrm{m}^{-3}$ ) mirrored the abundance pattern, except for the coastal water outside Tanafjord, where the biomass was high (1 to $1.5 \times 10^{5} \mu \mathrm{g} \mathrm{C} \mathrm{m}^{-3}$ ) and low abundance ( 2 to $3 \times$ $10^{3}$ ind. $\left.\mathrm{m}^{-3}\right)$.

\section{Zooplankton size spectra (Fig. 5)}

In Phase 1 there was a difference in abundance below and above $50 \mathrm{~m}$ depth in the coastal water just outside the 2 fjords Porsangerfjord and Laksefjord. We therefore plotted the size spectra for the 2 depth intervals 0 to $50 \mathrm{~m}$ and 50 to $100 \mathrm{~m}$ (Fig. 5A,B). The higher abundance of zooplankton below $50 \mathrm{~m}$ was mostly due to small zooplankton, as indicated by the increased biovolume in the size range 0.25 to $1 \mathrm{~mm} \mathrm{ESD} \mathrm{(Fig.} \mathrm{5B).}$ In Phase 2, the size spectrum in oceanic water on the eastern side increased from 0.5 to $2 \mathrm{~mm} \mathrm{ESD}$, and was 1 order of magnitude higher than the size spectrum in 

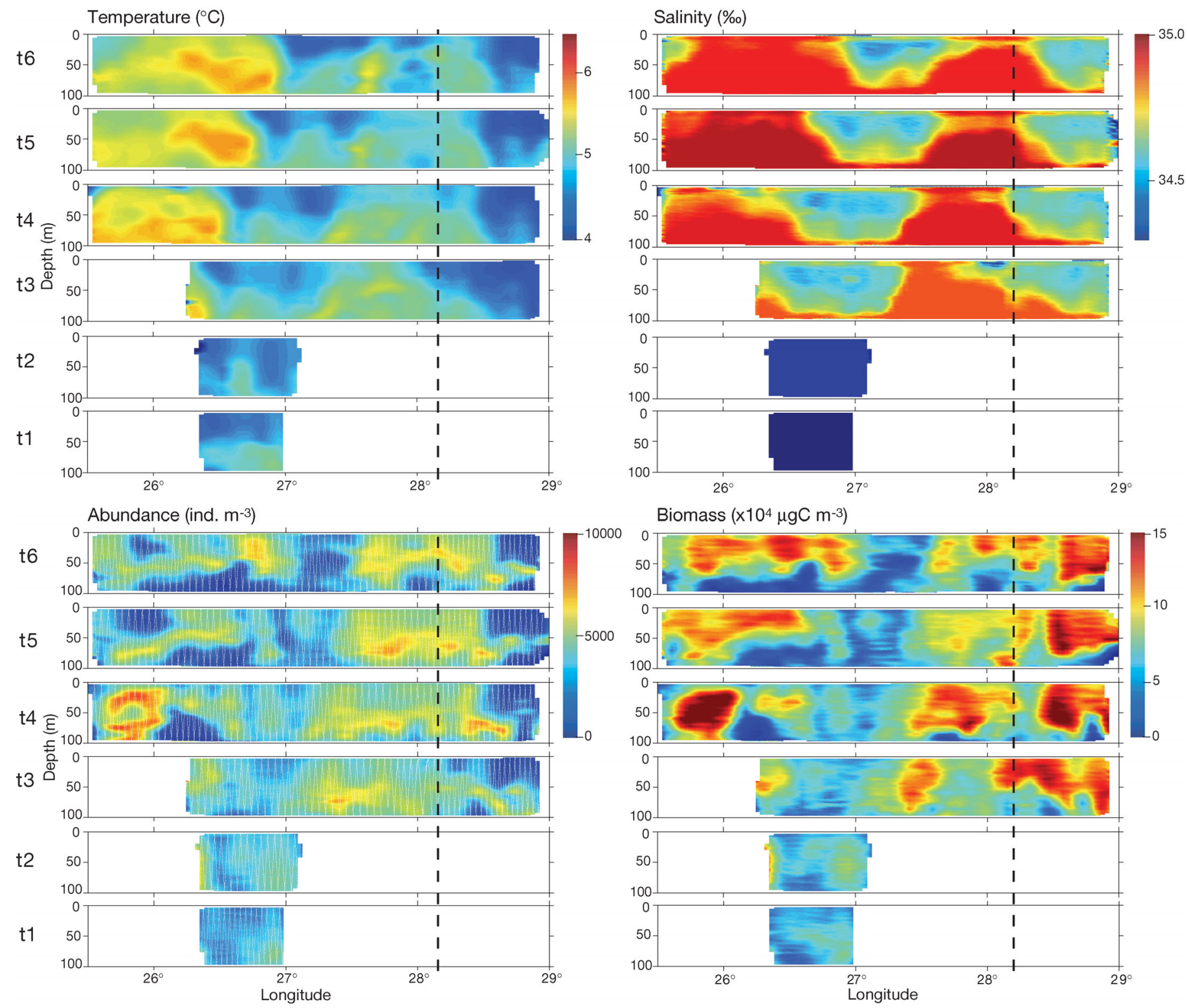

Fig. 4. Temperature $\left({ }^{\circ} \mathrm{C}\right)$, salinity $(\%)$, abundance (ind. $\mathrm{m}^{-3}$ ) and biomass $\left(\mu \mathrm{g} \mathrm{C} \mathrm{m}^{-3}\right)$ of zooplankton along the major transects (t1 to t6) in the southern Barents Sea in Phase 3 (28 to 30 May). Vertical dashed line indicates where transects continued S-E outside Tanafjord

the coastal water on the western side, which was relatively linear (Fig. 5C,D). In Phase 3, the size spectra of the 2 outer areas with oceanic water (data not illustrated) was similar to the spectrum of the oceanic part of the outer area in Phase 2 (Fig. 5D). All these spectra peaked around $1 \mathrm{~mm}$ ESD. On the other hand, the size spectra of the 2 coastal waters (outside the 2 fjords) were quite different from each other (Fig. 5E,F) and also from the spectra of oceanic waters. The spectrum of the coastal water outside Porsangerfjord was linear from 0.5 to $2.5 \mathrm{~mm}$ ESD and lower than that of oceanic water (Fig. 5E). It was similar to the spectrum of the coastal part of the outer area in Phase 2 (Fig. 5C), but different from the spectrum of the coastal water at the same location in Phase 1 (Fig. 5A,B). The size spectrum of the coastal water outside Tanafjord was more similar to the spectra in oceanic water. However, the peak was around $1.3 \mathrm{~mm}$ ESD in the size spectrum of the coastal water outside Tanafjord (Fig. 5F), while it was around $1 \mathrm{~mm}$ ESD in the size spectra typical of oceanic water.

\section{Currents and abundance in eddies (Fig. 6)}

Pedersen et al. (2005) calculated the relative geostrophical current for the study area (based on den- 


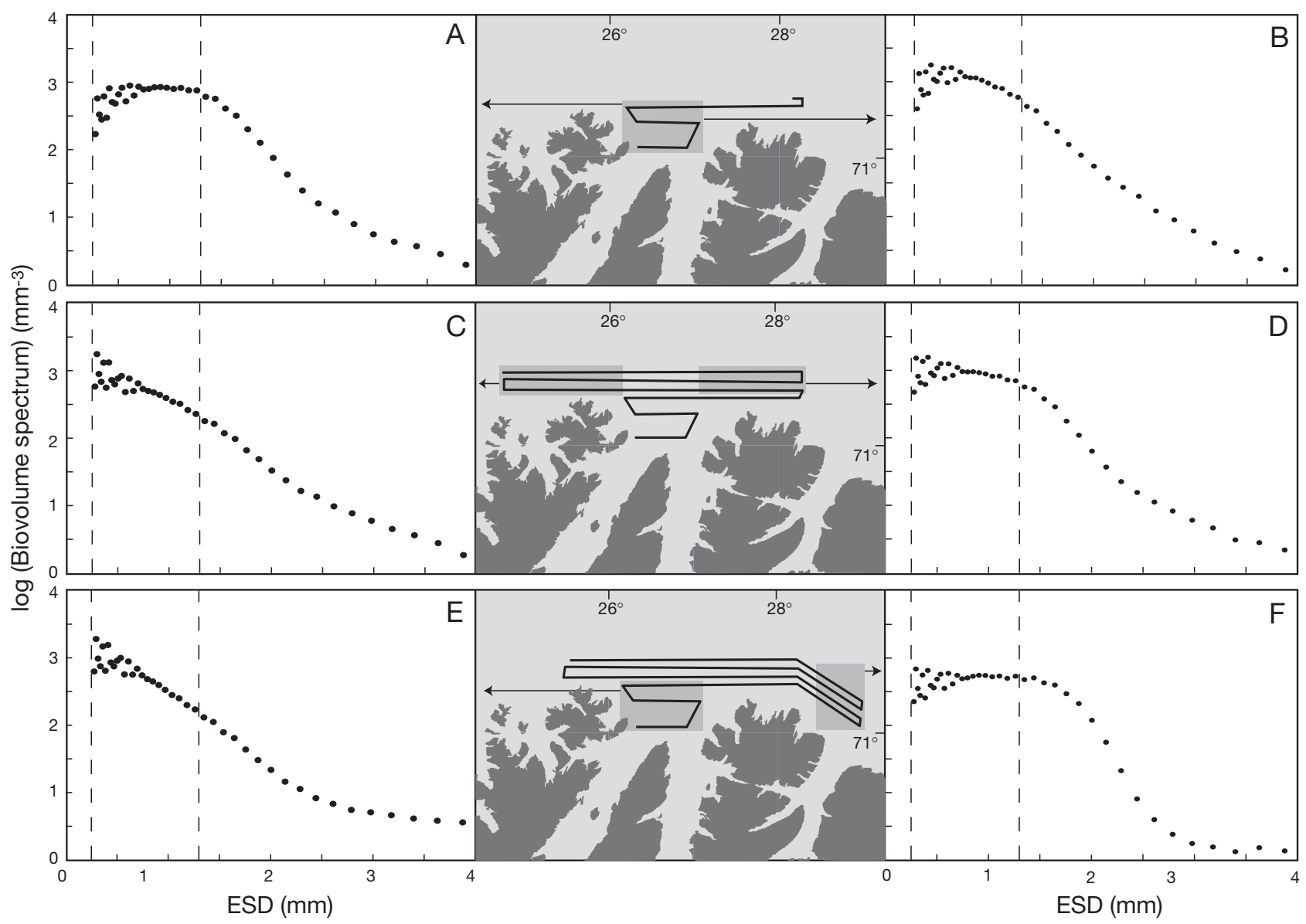

Fig. 5. Biovolume size spectra during Phases 1 to 3 (top, middle and lower rows, respectively) in coastal water outside Porsanger and Laksefjord at (A) 0 to $50 \mathrm{~m}$ and (B) 50 to $100 \mathrm{~m}$ depth; in outer area (C) coastal water and (D) oceanic water; and in (E) coastal water outside Porsanger and Laksefjord and (F) coastal water outside Tanafjord. Vertical dashed lines indicate ESD at 0.25 mm (detection limit of optical plankton counter) and at $1.3 \mathrm{~mm}$ (mean size for capelin Mallotus villosus larvae)

sity measurements from the CTD on the SCANFISH, see their paper for more details). Their results show the presence of several mesoscale eddies. Anti-cyclonic eddies contained water of low salinity, while cyclonic eddies contained water of higher salinity. We overlaid the zooplankton abundance field with the current field at $50 \mathrm{~m}$ depth from Phases 1, 2 and 3 to show the correlation between the biological information and the mesoscale circulations (Fig. 6).

In Phase 1 an anti-cyclonic eddy with coastal water was apparent close to the outlet of the 2 fjords (Fig. 6: top panel). The abundance of zooplankton in this eddy was low above $50 \mathrm{~m}$ depth, with values around 3 to $4 \times$ $10^{3}$ ind. $\mathrm{m}^{-3}$, and high below $50 \mathrm{~m}$ depth, with values around $6.5 \times 10^{3}$ ind. $\mathrm{m}^{-3}$ (Fig. 2). In the east, 2 cyclonic eddies with oceanic water was identified, and along the western rim of our study area strong currents prevailed. In Phase 2 (Fig. 6: middle panel) a cyclonic eddy in the central area consisted of oceanic water and high zooplankton abundance, with maximum values $\sim 7$ to $8 \times 10^{3}$ ind. $\mathrm{m}^{-3}$ (Fig. 3: t3), while meanders occurred further offshelf. Abundance of zooplankton in the meanders varied with depth and area, being lower on the western side (Fig. 3: t4 west, $3 \times 10^{3}$ ind. $\mathrm{m}^{-3}$ ) where coastal water dominated, and higher on the eastern side (Fig. 3: t4 east, $7 \times 10^{3}$ ind. $\mathrm{m}^{-3}$ ) within oceanic water. The abundance was also high $(6$ to $7 \times$ $10^{3}$ ind $\mathrm{m}^{-3}$ ) in the frontal zone between the meanders and the cyclonic eddy.

In Phase 3 (Fig. 6: bottom panel) an anti-cyclonic eddy with coastal water and low abundance (Fig. 4: 3 to $4 \times 10^{3}$ ind. $\mathrm{m}^{-3}$ ) was present just outside the 2 fjords. Further offshelf (Fig. 4: t4 west, $8 \times 10^{3}$ ind. $\mathrm{m}^{-3}$; and $\mathrm{t} 4$ east, $6 \times 10^{3}$ ind. $\mathrm{m}^{-3}$ ) 2 cyclonic eddies with oceanic waters and high zooplankton abundances were found. A fourth eddy was also identified in the eastern part of the study area, outside Tanafjord. This anti-cyclonic eddy consisted of coastal water and had a low abundance of zooplankton ( 1 to $2 \times 10^{3}$ ind. $\mathrm{m}^{-3}$ ). Statistical tests show that the 2 cyclonic eddies contained significantly higher abundances of zooplankton than the 2 anti-cyclonic eddies (ANOVA, p $<0.05$, Tables 1 to 3 ). 

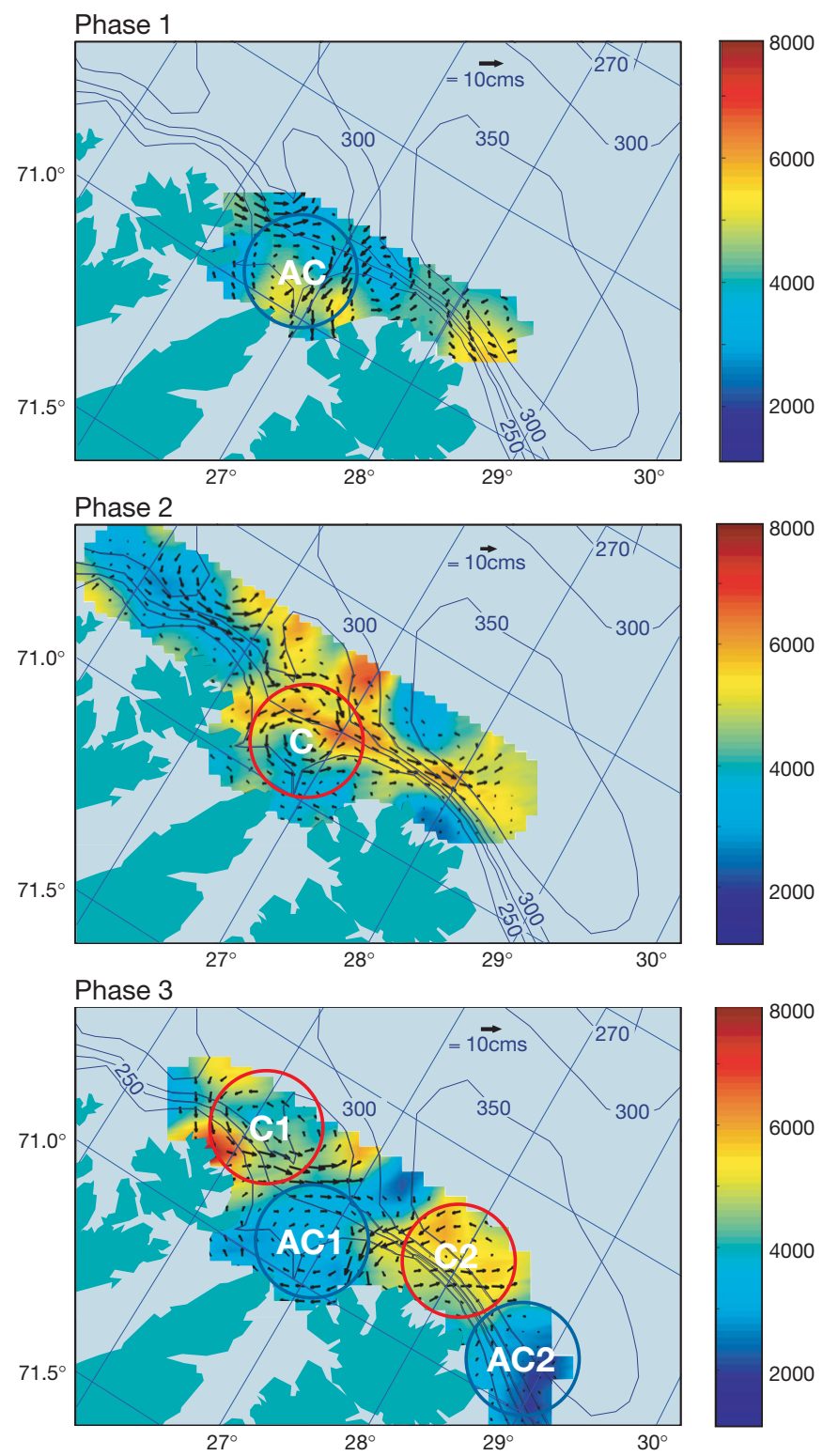

Fig. 6. Geostrophical current (arrows) and abundance (right colour bar, ind. $\mathrm{m}^{-3}$ ) of zooplankton at $50 \mathrm{~m}$ depth outside Porsanger, Laksefjord and Tanafjord in Phases 1 to 3. AC: anti-cyclonic eddy; C: cyclonic eddy

\section{Zooplankton species in MOCNESS}

In the study area, the zooplankton consisted essentially of copepods, which made up $82.2 \%$ of total abundance and comprised mainly Calanus finmarchicus (55.6\%), Oithona similis (11.8\%) and copepod nauplii $(10.8 \%)$. Metridia spp. CI to III $(2.2 \%)$ and Oncaea borealis F $(1.8 \%)$ were found in low proportions. Other groups were Oikopleura spp. (5.7\%), euphausiids $(3.8 \%)$, echinoderm larvae $(2.1 \%)$ and capelin larvae $(\sim 1 \%)$. The remaining group of species (>20) accounted for $5.2 \%$ of the total abundance in the net tows.
Table 1. Results of 2-factor ANOVA (transect and eddy) on physical structures identified during Phase 3 (28 to 30 May) (see Fig. 6). $H_{0}$ : there are no differences in particle abundance between different physical structures (eddies)

\begin{tabular}{|lrrrrrrr|}
\hline $\begin{array}{l}\text { Source of } \\
\text { variation }\end{array}$ & SS & df & MS & \multicolumn{1}{c|}{$F$} & p & $F_{\text {crit }}$ \\
\hline Transect & 5381093 & 2 & 2690547 & 4.99 & 0.00866 & 3.09 \\
Eddy & 91010167 & 3 & 30336722 & 56.29 & 0.00000 & 2.70 \\
Interaction & 16174238 & 6 & 2695706 & 5.00 & 0.00017 & 2.19 \\
Within & 51739139 & 96 & 538949 & & & \\
Total & 164304637 & 107 & & & & \\
\hline
\end{tabular}

Table 2. Mean $\left( \pm \mathrm{SE}\right.$ ) abundance of particles (ind. $\mathrm{m}^{-3}$ ) in eddies (C: cyclonic; AC: anti-cyclonic) along Transects t4, t5 and t6 during Phase 3

\begin{tabular}{|lcccc|}
\hline \multirow{2}{*}{ Transect } & \multicolumn{5}{c|}{ Ed Eddy } & C2 & AC2 \\
\cline { 2 - 5 } & C1 & AC1 & & \\
\hline t4 & $5295 \pm 564$ & $3664 \pm 193$ & $4669 \pm 141$ & $2777 \pm 288$ \\
t5 & $3850 \pm 141$ & $3141 \pm 194$ & $5647 \pm 117$ & $2408 \pm 131$ \\
t6 & $3917 \pm 158$ & $2861 \pm 153$ & $4671 \pm 253$ & $2793 \pm 243$ \\
\hline
\end{tabular}

Table 3. Student's $t$-tests (with Bonferroni corrections) comparing particle abundance in eddies (C: cyclonic; AC: anticyclonic) in Transects 4 to 6 . ${ }^{*}$ Significant difference at $\mathrm{p}<$ 0.05 between eddies; ns: no significant difference

\begin{tabular}{lccccccccccc|}
\hline Eddy & & AC1 & & & C2 & & & AC2 & \\
& t4 & t5 & t6 & t4 & t5 & t6 & t4 & t5 & t6 \\
\hline C1 & ns & ns & $*$ & & ns & $*$ & ns & $*$ & $*$ & $*$ \\
AC1 & & & & & $*$ & $*$ & $*$ & ns & ns & ns \\
C2 & & & & & & & ${ }^{*}$ & $*$ & $*$ \\
\hline
\end{tabular}

\section{DISCUSSION}

\section{Zooplankton abundance and biomass}

We found distinct differences in zooplankton abundance and biomass between coastal and oceanic waters in our study area. The water masses were distinguished by temperature and salinity. Zooplankton abundance and biomass were higher in oceanic waters than in coastal waters (Figs. 2 to 4). This trend is consistent with the findings of Dalpadado et al. (2003), who found the highest abundance and biomass of zooplankton in Atlantic water, followed by mixed coastal and Atlantic water (termed 'oceanic' in the present study), while coastal water displayed low abundances. Dalpadado et al.'s (2003) study was conducted in the Barents Sea from August to October in 1986 to 2000, and although their data are from autumn and ours from spring, we can assume that there may be persistent 
abundance and biomass differences between these 2 water types throughout the year. Falkenhaug et al. (1997) examined the zooplankton community within a fjord in northern Norway during spring and found that the community structure changed from the innermost to the outermost stations concurrent with changes in the hydrographic structure. They also found that the abundance of the recruiting generation of Calanus finmarchicus steadily increased from the outer to the inner stations during the productive season (minimum in March to maximum in July/August), demonstrating that $C$. finmarchicus was advected from the outer area into the fjord during this time. In the early part of the productive season, the abundant $C$. finmarchicus has its source area offshelf and is transported steadily onto the shelf, i.e. the source populations of zooplankton clearly differ between coastal and oceanic waters, explaining the differences in abundance and biomass in different types of water. On-shelf transport of zooplankton biomass (primarily composed of C. finmarchicus) is a unique feature of northern Norwegian coastal regions, which enhances coastal biomass build-up during the early part of the productive summer season (Tande 1991). This may differ from other coastal productive areas, such as the California Current and the Benguela Current, where local zooplankton productivity is driven by upwelling and enhanced primary production.

\section{Eddies}

The area investigated was highly dynamic, with rapid changes in currents and in the properties of the water masses. The hydrodynamic conditions are described by Pedersen et al. (2005), whose study revealed non-linear mesoscale eddies translating eastward, following the shelf break. Anti-cyclonic eddies contained coastal water, while cyclonic eddies contained oceanic water. In further offshore areas, meanders and mesoscale jets were found. The properties of the water masses indicated mixing between warm, saline Atlantic water and cold, less saline Norwegian coastal water. The translation speed of these mesoscale eddies was approximately $7 \mathrm{~km} \mathrm{~d}^{-1}$. Their formation is due to interactions between the Norwegian Coastal Current and bathymetric irregularities (Ikeda et al. 1989).

A 2-factor (transect and eddy) ANOVA revealed significant abundance differences in the 4 eddies identified in Phase 3 (Table 1). The 3 outer transects (Factor 1) were also significantly different $(p<0.01)$ from each other, probably representing a change from a coastal (fewer particles) to an oceanic (more particles) regime. More importantly, the eddy factor
(Factor 2) was highly significant ( $p<0.000)$, representing synchrony between cyclonic eddies and particle abundance, and the post-hoc $t$-test pattern is close to an optimal diagonal diagram: $(\mathrm{C} 1=\mathrm{C} 2) \neq(\mathrm{AC} 1=$ $\mathrm{AC2}$ ), where $\mathrm{C}=$ cyclonic and $\mathrm{AC}=$ anticyclonic (Table 3 ). The interaction term (transect $\times$ eddy) was also significant, probably due to the fact that the 2 anti-cyclonic eddies are closer to the coast (see Fig. 6, bottom panel).

Cyclonic eddies have been shown to affect abundance and distribution of plankton and fish larvae by entrapment of planktonic organisms (Nakata et al. 2000, Okazaki et al. 2002), and can play an important role in primary production through upwelling of nutrient rich deep water to the euphotic surface layer. This may then cause enhanced zooplankton production followed by increased ichthyoplankton survival and recruitment (Kimura et al. 1997, Nakata et al. 2000). For an upwelling event to have any effect on secondary production, the cyclonic eddies would have to endure for several weeks (Dower \& Mackas 1996), whereas the eddies in our study area are believed to endure over a temporal scale of days (or at most 1 to 2 wk: Dag Slagstad, SINTEF, Trondheim, Norway, pers. comm.). Consequently, any upwelling and subsequent phytoplankton growth in these cyclonic eddies would be to short-lived to induce development and growth of zooplankton.

\section{Biological composition of eddies}

During our study, the cyclonic eddies all contained oceanic water, high zooplankton abundance and biomass (for Phase 3, see Table 2). The shapes of the size spectra found in cyclonic eddies were also similar, and it is therefore probable that their biological composition was similar, since the waters in these eddies were of the same origin. The 3 anti-cyclonic eddies were all near-shore and contained water of coastal origin, with low abundance of zooplankton. However, as there was a clear variation in biomass and the shape of their size spectra also differed, their biological composition must also have differed (Fig. 5A,B,E,F). What is the cause for differences in zooplankton composition within coastal waters? A variable degree of mixing between coastal and oceanic waters may play a role, since the abundant zooplankton in cyclonic eddies eventually will be mixed with those in coastal waters as these eddies erode and disintegrate (Dalpadado et al. 2003). By definition, coastal water has salinities below 34.5\%, while Atlantic water has salinities higher than $34.95 \%$ (Rey 1981), and shelf water is a mixture of the two. During Phase 3, the coastal water outside Porsanger- 
fjord and Laksefjord (Fig. 5E) was not influenced by oceanic water (as can be inferred from the salinity of $<34.5 \%$ : see $\mathrm{t} 1$ and t2 in Fig. 4 ), and biomass was low. The coastal water in the same position in Phase 1 was influenced more strongly by oceanic water (salinity $\sim 34.7 \%$ : see t1 and t2 in Fig. 2), and abundance and biomass were higher (Fig. 5B). Contrary to the effect of advection, we believe that in the coastal water outside Tanafjord in Phase 3 (Fig. 5F), the enhanced biomass derives from the coastal area through variable hatching of capelin larvae (see next subsection).

\section{Capelin larvae}

In the anti-cyclonic eddy, consisting of coastal water near the outlet of Tanafjord in Phase 3, the OPC size spectrum differed from that of other areas (Fig. 5F). It showed low abundance, but high biomass and a distinct peak around $1.3 \mathrm{~mm}$ ESD, which, based on our findings in net tow samples, we interpret as being due to newly hatched capelin larvae. The average size of capelin larvae just after hatching is approximately $1.21( \pm 0.17) \mathrm{mm}$ ESD (measured using the same field-OPC in our laboratory). Net tows were conducted in the area occupied by the anti-cyclonic eddy $3 \mathrm{~d}$ prior to the OPC transects in Phase 3. Capelin larvae were found in the net samples at all stations outside Tanafjord. The net tow samples confirm the patchy distribution of the capelin larvae, which contributed 5 to $38 \%$ of total abundance at the various stations. There were only a few net tows covering a very limited area, which may well have missed dense capelin larvae patches, whereas the towed SCANFISH-OPC measurements covered a much larger area, and provided more accurate estimates of their distribution. Since this area is highly dynamic, with coastal jets and translating eddies (Pedersen et al. 2005), the water mass can be replaced in certain areas within a few days. However, it is likely that larvae were continuously hatching in the area throughout the whole sampling period in May.

Within the size range of capelin larvae $(1.21 \pm$ $0.17 \mathrm{~mm}$ ), only Calanus finmarchicus CIV, Oikopleura spp. and capelin larvae contributed to zooplankton abundance. When zooplankton in coastal water are enriched by a cohort of recruiting $C$. finmarchicus, consisting of Stages CI to CIV in a parcel of oceanic water, a peak should occur between 0.5 and $1.5 \mathrm{~mm}$ ESD (the ESD range of CI to CIV larvae). As no such peak occurred in the size spectrum (which remained low at $<1 \mathrm{~mm}$ ESD), we therefore believe that the increased biomass was not due to a pulse of $C$. fin- marchicus CIV (i.e. mixing of waters). The larvaceans Oikopleura spp. are fast-growing opportunists that can double their abundance in a period of a few days (Dower \& Mackas 1996), but patches of Oikopleura spp. have not previously been recorded in the southern Barents Sea (Henriksen 2000). Thus, we conclude that capelin larvae predominately contributed to this size range in the size spectrum (Fig. 5F).

\section{Importance of eddies for capelin recruitment}

The eddies in the spawning and hatching habitat of capelin in the southern Barents Sea are formed by different mechanisms (Ikeda et al. 1989, Johannessen et al. 1989) and are relatively small and of short duration (Loeng \& Sætre 2001, Ingvaldsen et al. 2002). However, their impact on the biological community can be significant, by transporting biota into the region as food supplies, or transporting larvae out of this region. On the east coast of North America, meandering fronts along the shelf break create rings and eddies which carry large volumes of waters offshelf into the Sargasso Sea, significantly reducing the successful recruitment of fish species on the shelf (Wroblewski \& Cheney 1984). Meanders and eddies also exist in our study area. Although the most significant eddy transport follows the shelf, it is also clear that mesoscale eddies are translated on-shelf (Pedersen et al. 2005). The intrusion of eddies of oceanic water and plankton (both meso- and protozoan) onto the shelf may increase the temperature, provide food for fish larvae and seed the shelf water, before being eroded. The anti-cyclonic eddies are most probably formed through the interaction of fronts, jets and topographic steering. The absolute impact of these eddies on growth and survival conditions of the entrapped capelin larvae are still unknown. However, it is clear that these physical features will transport capelin larvae to offshelf regions, where mortality may be minimised through higher growth rates due to elevated food supply and temperature (Pepin 1991). Thus, the number of springtime eddies formed and their phasing with the spawning and hatching cycle can be important to capelin recruitment variability (Logerwell \& Smith 2001, Logerwell et al. 2001).

Acknowledgements. The authors wish to thank the captain and crew of RV 'Jan Mayen' and participants of the BAS 2 cruise in May 2001. This work was financially supported by the Research Council of Norway through the strategic programme BASECOEX, project no. 140290/140 and through a travel fund for M.F. from the Research Council of Norway project no. 158023. We also want to thank all the members of Meng Zhou's Laboraty at EEOS, UMass, Boston, and our graphic designers Frøydis Strand and Fride Toning. 


\section{LITERATURE CITED}

Bang ND (1973) Characteristics of an intense ocean frontal system in the upwell regime west of Cape Town. Tellus 25: 256-265

Boehlert GW, Watson W, Sun LC (1992) Horizontal and vertical distributions of larval fishes around an isolated oceanic island in the tropical Pacific. Deep-Sea Res 39:439-466

Bograd SJ, Stabeno PJ, Schumacher JD (1994) A census of mesoscale eddies in Shelikof Strait, Alaska, during 1989. J Geophys Res 99:18243-18254

Bretherton FP, Davis RE, Fandry CB (1976) A technique for objective analysis and design of oceanographic experiments applied to MODE-73. Deep-Sea Res 23:559-582

Canino MF, Bailey KM, Incze LS (1991) Temporal and geographic differences in feeding and nutritional condition of walleye pollock larvae Theragra chalcogramma in Shelikof Strait, Gulf of Alaska. Mar Ecol Prog Ser 79:27-35

Csanady GT (1979) Birth and death of a warm core ring. J Geophys Res 84:777-780

Dalpadado P, Ingvaldsen R, Hassel A (2003) Zooplankton biomass variation in relation to climatic conditions in the Barents Sea. Polar Biol 26:233-241

Dower JF, Mackas DL (1996) 'Seamount effects' in the zooplankton community near Cobb Seamount. Deep-Sea Res I 43:837-858

Edvardsen A, Zhou M, Tande KS, Zhu YW (2002) Zooplankton population dynamics: measuring in situ growth and mortality rates using an optical plankton counter. Mar Ecol Prog Ser 227:205-219

Falkenhaug T, Tande K, Timonin A (1997) Spatio-temporal patterns in the copepod community in Malangen, Northern Norway. J Plankton Res 19:449-468

Gandin L (1965) Objective analysis for meteorological fields. Israel Program for Scientific Translations, Jerusalem

Gjøsæter H (1998) The population biology and exploitation of capelin (Mallotus villosus) in the Barents Sea. Sarsia 83: 453-496

Halvorsen E, Tande KS, Edvardsen A, Slagstad D, Pedersen OP (2003) Habitat selection of overwintering Calanus finmarchicus in the NE Norwegian Sea and shelf waters off Northern Norway in 2000-02. Fish Oceanogr 12:339-351

Harms IH (1992) A numerical study of the barotropic circulation in the Barents and Kara Seas. Cont Shelf Res 12:1043-1058

Henriksen JF (2000) The importance of appendicularians (Tunicata: Larvacea) in the Barents Sea and adjacent waters. C Sci thesis, University of Tromsø

Herman AW (1988) Simultaneous measurement of zooplankton and light attenuance with a new optical plankton counter. Cont Shelf Res 8:205-221

Herman AW (1992) Design and calibration of a new optical plankton counter capable of sizing small zooplankton. Deep-Sea Res 39:395-415

Hinckley S, Hermann AJ, Mier KL, Megrey BA (2001) Importance of spawning location and timing to successful transport to nursery areas: a simulation study of Gulf of Alaska walleye pollock. ICES J Mar Sci 58:1042-1052

Huang WG, Cracknell AP, Vaughan RA, Davies PA (1991) A satellite and field view of the Irish Shelf front. Cont Shelf Res 11:543-562

Huntley ME, Zhou M, Nordhausen W (1995) Mesoscale distribution of zooplankton in the California Current in late spring, observed by optical plankton counter. J Mar Res 53:647-674

Ikeda M, Johannessen JA, Lygre K, Sandven S (1989) A process study of mesoscale meanders and eddies in the Norwegian Coastal Current. J Phys Oceanogr 19:20-35
Ingvaldsen R, Loeng $H$, Asplin L (2002) Variability in the Atlantic inflow to the Barents Sea based on a one-year time series from moored current meters. Cont Shelf Res 22:505-519

Johannessen JA, Svendsen E, Sandven S, Johannessen OM, Lygre K (1989) Three-dimensional structure of mesoscale eddies in the Norwegian Coastal Current. J Phys Oceanogr 19:3-19

Kasai A, Kimura S, Nakata H, Okazaki Y (2002) Entrainment of coastal water into a frontal eddy of the Kuroshio and its biological significance. J Mar Syst 37:185-198

Kimura S, Kasai A, Nakata H, Sugimoto T, Simpson JH, Cheok JVS (1997) Biological productivity of meso-scale eddies caused by frontal disturbances in the Kuroshio. ICES J Mar Sci 54:179-192

Komatsu T, Sugimoto T, Ishida K, Itaya K, Mishra P, Miura T (2002) Importance of the Shatsky Rise area in the Kuroshio Extension as an offshore nursery ground for Japanese anchovy (Engraulis japonicus) and sardine (Sardinops melanostictus). Fish Oceanogr 11:354-360

Lee TN, Mayer DA (1977) Low-frequency current variability and spin-off eddies along the shelf off southeast Florida. J Mar Res 35:193-220

Lobel PS, Robinson AR (1986) Transport and entrapment of fish larvae by ocean mesoscale eddies and currents in Hawaiian waters. Deep-Sea Res 33:483-500

Loeng H (1991) Features of the physical oceanographic conditions of the Barents Sea. Polar Res 10:5-18

Loeng H, Sætre R (2001) Features of the Barents Sea circulation. Report No. 1. Institute of Marine Research, Bergen

Logerwell EA, Smith PE (2001) Mesoscale eddies and survival of late stage Pacific sardine (Sardinops sagax) larvae. Fish Oceanogr 10:13-25

Logerwell EA, Lavaniegos B, Smith PE (2001) Spatiallyexplicit bioenergetics of Pacific sardine in the Southern California Bight: are mesoscale eddies areas of exceptional prerecruit production? Prog Oceanogr 49:391-406

McClimans TA, Nilsen JH (1993) Laboratory simulation of the ocean currents in the Barents Sea. Dyn Atmos Oceans 19: $3-25$

Nakata H, Kimura S, Okazaki Y, Kasai A (2000) Implications of meso-scale eddies caused by frontal disturbances of the Kuroshio Current for anchovy recruitment. ICES J Mar Sci 57:143-151

Okazaki Y, Nakata H, Kimura S (2002) Effects of frontal eddies on the distribution and food availability of anchovy larvae in the Kuroshio Extension. Mar Freshw Res 53: 403-410

Okazaki Y, Nakata H, Kimura S, Kasai A (2003) Offshore entrainment of anchovy larvae and its implication for their survival in a frontal region of the Kuroshio. Mar Ecol Prog Ser 248:237-244

Pedersen OP, Slagstad D, Tande KS (2003) Hydrodynamic model forecasts as a guide for process studies on plankton and larval fish. Fish Oceanogr 12:369-380

Pedersen OP, Zhou M, Tande KS, Edvardsen A (2005) Eddy formation on the coast of North Norway-evidenced by synoptic sampling. ICES J Mar Sci 62:615-628

Pepin P (1991) Effect of temperature and size on development, mortality, and survival rates of the pelagic early lifehistory stages of marine fish. Can J Fish Aquat Sci 48: 503-518

Platt T, Denman K (1978) The structure of pelagic marine ecosystems. Rapp P-V Réun Cons Int Explor Mer 173: 60-65

Rey F (1981) The development of the spring phytoplankton outburst at selected sites off the Norwegian coast. In: 
Sæetre R, Mork M (eds) The Norwegian Coastal Current, Vol 2. University of Bergen, Bergen, p 649-680

Rodriguez J, Mullin MM (1986) Relation between biomass and body weight of plankton in a steady state oceanic ecosystem. Limnol Oceanogr 31:361-370

Rodriguez JM, Barton ED, Eve L, Hernandez-Leon S (2001) Mesozooplankton and ichthyoplankton distribution around Gran Canaria, an oceanic island in the NE Atlantic. DeepSea Res I 48:2161-2183

Schumacher JD, Stabeno PJ, Bograd SJ (1993) Characteristics of an eddy over a continental shelf: Shelikof Strait, Alaska. J Geophys Res 98:8395-8404

Sheldon RW, Parsons TR (1967) A continuous size spectrum for particulate matter in sea. J Fish Res Board Can 24: 909-915

Silvert W, Platt T (1978) Energy flux in the pelagic ecosystem: a time-dependent equation. Limnol Oceanogr 23: 813-816

Editorial responsibility: Otto Kinne (Editor-in-Chief), Oldendorf/Luhe, Germany
Tande KS (1991) Calanus in North Norwegian fjords and in the Barents Sea. Polar Res 10:389-407

Wiebe PH, Burt KH, Boyd SH, Morton AW (1976) A multiple opening/closing net and environmental sensing system for sampling zooplankton. J Mar Res 34:313-326

Wiebe PH, Morton AW, Bradley AM, Backus RH, Craddock JE, Barber V, Cowles TJ, Flierl GR (1985) New developments in the MOCNESS, an apparatus for sampling zooplankton and micronekton. Mar Biol 87:313-323

Wroblewski JS, Cheney J (1984) Ichthyoplankton associated with a warm core ring off the Scotian Shelf. Can J Fish Aquat Sci 41:294-303

Zhou M (1998) An objective interpolation method for spatiotemporal distribution of marine plankton. Mar Ecol Prog Ser 174:197-206

Zhou M, Huntley ME (1997) Population dynamics theory of plankton based on biomass spectra. Mar Ecol Prog Ser 159:61-73

Submitted: November 30, 2004; Accepted: April 12, 2005 Proofs received from author(s): August 31, 2005 